Title: Autonomous Biomorphic Robots as Platforms for Sensors

Author(s):

Mark Tilden, P-21

fin

OCT 11 MOP

Brosl Hasslacher, T-13

ar

Ronnie Mainieri, T-13

John Moses, P-21

Submitted to:

DOE Office of Scientific and Technical Information (OSTI)

DHSTRIBUTION OF THIS DOCUNENT IS UNLHMTED
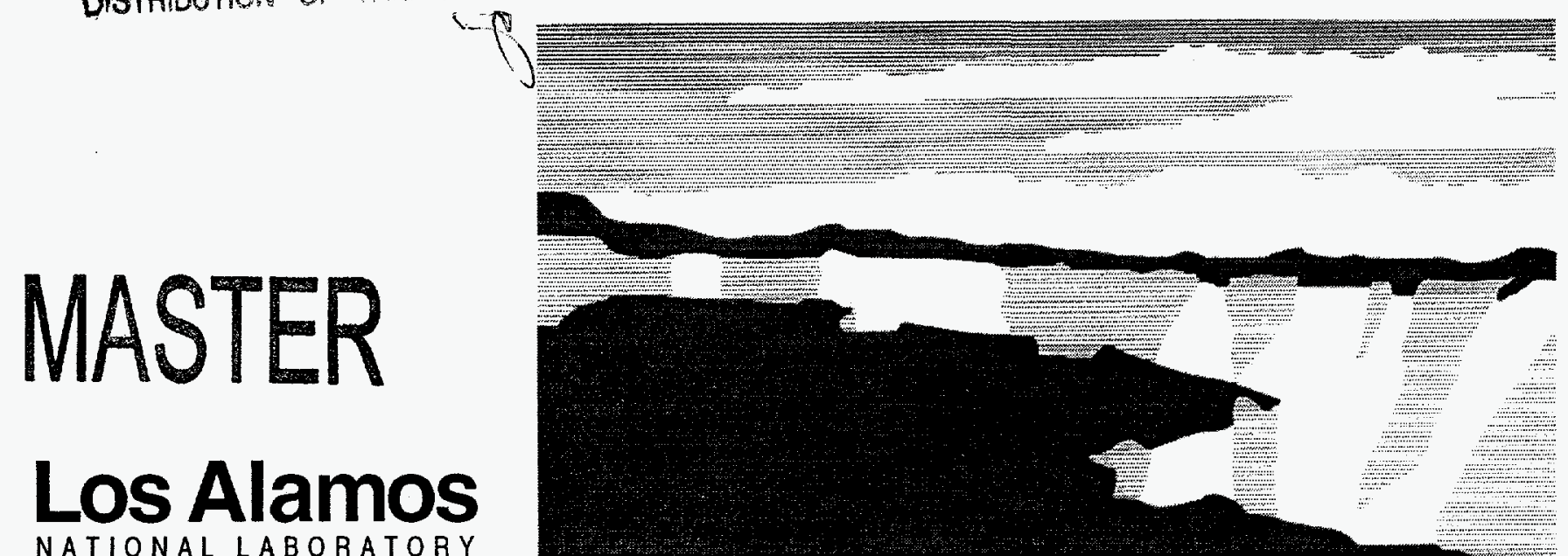

Los Alamos National Laboralory, an affirmative action/equal opportunity employer, is operated by the Universily of California for the U.S. Department of Energy under contract W-7405-ENG-36. By acceptance of this anticle, the publisher recognizes that the U.S. Government retains a nonexclusive, royaltyfree license to publish or reproduce the published form of this contribution, or to allow others to do so, for U.S. Government purposes. The Los Alamos National Laboratory requests that the publisher identify this article as work performed under the auspices of the U.S. Department of Energy. 


\section{DISCLAIMER}

Portions of this document may be illegible in electronic image products. Images are produced from the best available original document. 


\title{
Autonomous Biomorphic Robots as Platforms for Sensors
}

\author{
Mark Tilden*, Brosl Hasslacher, Ronnie Mainieri, and John Moses
}

\begin{abstract}
This is the final report of a one-year, Laboratory-Directed Research and Development (LDRD) project at the Los Alamos National Laboratory (LANL). The idea of building autonomous robots that can carry out complex and nonrepetitive tasks is an old one, so far unrealized in any meaningful hardware. Tilden has shown recently that there are simple, processor-free solutions to building autonomous mobile machines that continuously adapt to unknown and hostile environments, are designed primarily to survive, and are extremely resistant to damage. These devices use smart mechanics and simple (low component count) electronic neuron control structures having the functionality of biological organisms from simple invertebrates to sophisticated members of the insect and crab family. These devices are paradigms for the development of autonomous machines that can carry out directed goals. The machine then becomes a robust survivalist platform that can carry sensors or instruments. These autonomous roving machines, now in an early stage of development (several proof-of-concept prototype walkers have been built), can be developed so that they are inexpensive, robust, and versatile carriers for a variety of instrument packages. Applications are immediate and many, in areas as diverse as prosthetics, medicine, space, construction, nanoscience, defense, remote sensing, environmental cleanup, and biotechnology.
\end{abstract}

\section{Background and Research Objectives}

Tilden ${ }^{1}$ has shown that there are simple, processorless solutions to building autonomous robotic devices that continuously adapt to their environment, are designed primarily to survive in hostile environments, and are extremely robust against damage.

*Principal investigator, e-mail: mwtilden@lanl.gov 
These devices are based on smart mechanics and simple (low component count) electronic neuron control structures that mimic the functionality of biological organisms from simple invertebrates to members of the insect and crab family.

Tilden architectures differ from conventional robots in both implementation and in the design emphasis. The robot body is designed to survive in the environment for which it is intended, and not to perform specific tasks in that environment. Once survivability is under control, goals can be superimposed and the machine used as a platform to carry sensors or other conventional instruments. For the implementation, the simple analog neural circuits are used for the control systems, rather than processors. Processors could be used as part of the sensor package and could influence the robot body by, for example, telling it where to go. This work continued the development of neuron-controlled autonomous machines and was directed toward machines that could carry and be controlled by such sensors. It included a test of prototypes in the field.

\section{Importance to LANL's Science and Technology Base and National R\&D Needs}

We believe that these roving machines, although now in an early stage of development, can within a few years be brought to the point that they can serve as inexpensive, robust, and versatile carriers for a variety of instruments. These instruments would target the mission of the platform, gather information, and direct the actions of the platform. They would not direct the means of carrying out those actions, because the robot is already designed to do that in an optimal way. A number of applications would be possible for such a robot, depending on the sensors. These could be, for example, chemical sniffers, magnetic detectors, radiation detectors, listening devices or recorders, cameras, or sample collectors. They would have application in a number of areas where safety or other problems make it difficult for humancarried sensors to gain access, such as mine clearing, remediation of unexploded ordnance, in surveillance for treaty verification, or for detection of the proliferation of weapons of mass destruction, such as chemical or nuclear weapons. The development of robotic devices whose controllers and mechanical systems are biologically inspired has the potential to offer insights into the function of those systems and thus, is complementary to purely biological studies of these systems. 


\section{Scientific Approach and Rresults to Date}

The work we describe evolved from the work of Brooks ${ }^{2}$ and his students at MIT, who through "subsumption architecture" substituted distributed control for the top-down architecture of earlier robots. Brooks further suggested that robots should be embedded in the world, learning dynamically about their environment and reacting to it. This is what is known as reaction-based architecture. Tilden's machines use distributed control systems, but they differ in architecture from those of Brooks by using simple, inexpensive analog components instead of complex digital processors as the basic control devices. Like the machines of Brooks, these machines are intended to operate in the real world.

The second influence on these designs, and the methodology which led to them, comes from biological morphology, both in the design of walking structures and the use of a central nervous system paradigm. In 1984 Braitenburg ${ }^{3}$ suggested that the best way to build robots is by real evolutionary techniques, rather than simulation. Tilden's work has followed this suggestion, starting with extremely simple solar-powered robots, which did little more than seek light (their food), and evolving toward more capable simple designs and to much more sophisticated and complex walkers that have the functionality of much more elaborate processor-based designs in a very compact and robust architecture.

The control structures of the Tilden walkers are controlled by circuits of typically six electronic "neurons" that functionally emulate biological central pattern generators (CPG), the neural circuits that control rhythmic movements such as chewing or walking in animals. The behavior of the CPG, and thus the walking patterns, can be modified by inputs from sensors such as antennae or photo sensors, by application specific sensors, or by controllers such as a processor. The electronic systems are coupled with biologically inspired mechanical structures that couple to the controllers to optimize structural and survival needs. The design approach is evolutionary, emphasizing the construction and observation of actual robots to evolve more effective designs.

The linchpin design principle is to avoid making robots that must do a specific task. The strategy is to develop robotic "creatures" that have no purpose, but to survive in a hostile environment, where survival means to move for their own purposes. Once robots can survive under most situations, it is then possible to tailor their designs to accomplish specific tasks. For example, a solar powered bug that wanders an apartment floor hunting for light sources can easily push a small brush or wiper, and thus dust the floor as it roves. A crab or spiderlike robot body can be controlled by an instrument that directs it to cover a certain area searching for regions of high nitrogen concentration, or for metals. The mechanical design of a robot body can be specialized to a particular task. For example, a mine detonator might be 
designed to have such a low blast cross section that it could survive several encounters with exploding mines and still function.

At least two types of machines have been developed that show promise as survivable platforms for sensors. The simplest are the turbots, in their present form two loosely coupled, two-neuron robot creatures sharing a single body and each controlling a mechanical flagella. They move by tumbling, the solar powered version showing phototropic behavior. Even in its present, relatively primitive form, the turbot excels at moving over rough terrain, indicating that such a device could be designed to carry sensors that are physically robust and insensitive to orientation.

Although the tumbling robots show promise, the emphasis in this work has been to increase the ability and survivability of walking machines controlled by simple neuron structures. A number of such devices have now been built, both by the principal investigator and by others trained by him. Earlier work was concentrated on the design and construction of machines that walked competently and on the incorporation of tactile and light sensors into the control systems. The work reported here concentrated on simplifying the electronic and mechanical systems and on developing solar-powered walkers and on field tests of these systems.

Beginning with battery-powered designs using five or more motors (Walkman and Spider) we have simplified the mechanical and control systems to a two-motor design, which has allowed us to build very energy-efficient robots that walk capably in a laboratory setting. Using inexpensive solar cells of about $7 \%$ efficiency, we have made small (typically $20-\mathrm{cm}$ long), lightweight machines that move nearly continuously under full sunlight. These devices were tested in field conditions at the Yuma Test Range, with the ultimate goal of providing sensor platforms for the remediation of unexploded ordnance. We assume that a reasonable sensor load that such a device would carry would be in the kilogram range, but tests to date are aimed simply at building devices that can move and survive in the field environment. We conducted tests on six robots, in full sunlight, with robots on concrete and on the ground. Ground conditions included sand, gravel, and the local malpais-mostly one to three centimeter rocks embedded in hard-baked soil. Temperatures near the ground in early afternoon ranged from 125 to 150 degrees Fahrenheit. As expected, these conditions provided a severe test of the technology in its current state.

The solar cells degraded in the heat to the point that the solar robots all failed, some sooner than others. This temperature sensitivity was unanticipated and peculiar to the cells used. We expect to replace them with cells of comparable efficiency and better heat tolerance. The control electronics for the devices tested worked successfully, except for circuitry used to 
initiate movement on two of the simpler robots. This problem may have been related to the failure of the solar cells and is not serious.

None of the simpler devices moved well on sand, gravel, and malpais. They failed typically by digging into sand rather than walking on it and by having their feet caught in embedded rocks in the malpais. It will take more complex machines, with more capable legs and feet, to successfully negotiate this environment. The most successful walker in rough terrain was a battery powered device with tactile sensors and built-in phototropism. It had pad feet and a simple rotating leg motion, which was energetic and persistent and that usually allowed it to work its way out of or around obstacles. Its success leaves us confident that useful sensors can be built using this technology.

\section{References:}

1. Hasslacher, B. and Tilden, M. W., "Living Machines," Robotics and Autonomous Systems: The Biology and Technology of Intelligent Autonomous Agents, L. Steels, Ed., Elsivier Publishers, Spring 1995.

2. Brooks, R., "The Whole Iguana," MIT Press Robotics Science, M. Brady, Ed., p. 432 (1989).

3. Braitenburg, V., "Vehicles: Experiments in Synthetic Psychology," MIT Press, Bradford Books, Cambridge, MA, 1984.

\section{DISCLAIMER}

This report was prepared as an account of work sponsored by an agency of the United States Government. Neither the United States Government nor any agency thereof, nor any of their employees, makes any warranty, express or implied, or assumes any legal liability or responsibility for the accuracy, completeness, or usefulness of any information, apparatus, product, or process disclosed, or represents that its use would not infringe privately owned rights. Reference herein to any specific commercial product, process, or service by trade name, trademark, manufacturer, or otherwise does not necessarily constitute or imply its endorsement, recommendation, or favoring by the United States Government or any agency thereof. The views and opinions of authors expressed herein do not necessarily state or reflect those of the United States Government or any agency thereof. 